\title{
The Lag From Money To Prices
}

\author{
KEITH M. CARLSON
}

$\mathbf{E}$ CONOMISTS generally agree that money affects prices with a lag. Research conducted at this Bank suggests that a change in the growth rate of money is fully reflected in the inflation rate in about five years. This conclusion was based on a statistical analysis of the relation between money and prices in the U.S. from 1955 through the 1960 s. $^{1}$

The length of the lag between money and prices represents important information that must be considered in the policy formulation process. The policymaker must allow for such lags when developing a policy to control inflation; he must also consider possible future impacts of short-run policies designed to combat recession. Given the historical presence of lags between money and prices, a policy designed to control inflation will not have immediate effects. The possible short-run costs (benefits) of a restrictive (stimulative) policy in terms of employment and output must be assessed against its longurun benefits (costs) in terms of the price level. The nature of the lag enters importantly into the decision to adopt a specific policy, whether it be short- or long-run in character.

The purpose of this article is to examine the relation between money and prices in light of the U.S.

\footnotetext{
Denis S. Karnosky, "The Link Between Money and Prices," this Review (June 1976), pp. 17-23. Also see Albert E. Burger, "Is Inflation All Due to Money?" this Review (December 1978), pp. 8-12.
}

economic experience of the 1970 s. Statistical results are summarized first and the economics of information and search are then summarized to provide a theoretical rationale for the results.

\section{Statistical Results}

Karnosky's original estimate of the price equation was based on the sample period from 1955 through mid-1971 and used what is now known as "old M1" for the money variable. A version of this equation, estimated by using the "new" MIB definition of money, is summarized in table $1 .^{2}$ Compared to the original results, using a different definition of money and modifying the sample period affects the pattern of the coefficients very little. The sum of the coefficients is one, as would be expected from economic theory. ${ }^{3}$ The mean lag is estimated at 10.96 quarters for the $1955-69$ sample period. ${ }^{4}$

${ }^{2} \mathrm{I} n$ this article, money is defined as M1B (currency plus checkable deposits at financial institutions). See R. W. Hafer, "The New Monetary Aggregates," this Review (February 1980), pp. 25-32. The sample period differs slightly from Karnosky's for purposes of balancing degrees of freedom, so that the 1970 s can be compared with the "pre-1970s".

${ }^{3}$ For a discussion of the theory, see Leonall $\mathrm{C}$. Andersen and Denis S. Kamosky, "The Appropriate Time Frame for Controlling Monetary Aggregates: The St. Louis Evidence," in Controlling Monetary Aggregates II: The Implementation, Conference Series No. 9. Federal Reserve Bank of Boston (September 1972), pp. 147-77.

4The mean lag serves as a summary measure of the speed with which prices respond to money. It is calculated as a sum of products (where each product is the coefficient times the number of the lag) divided by the sum of the coefficients. 


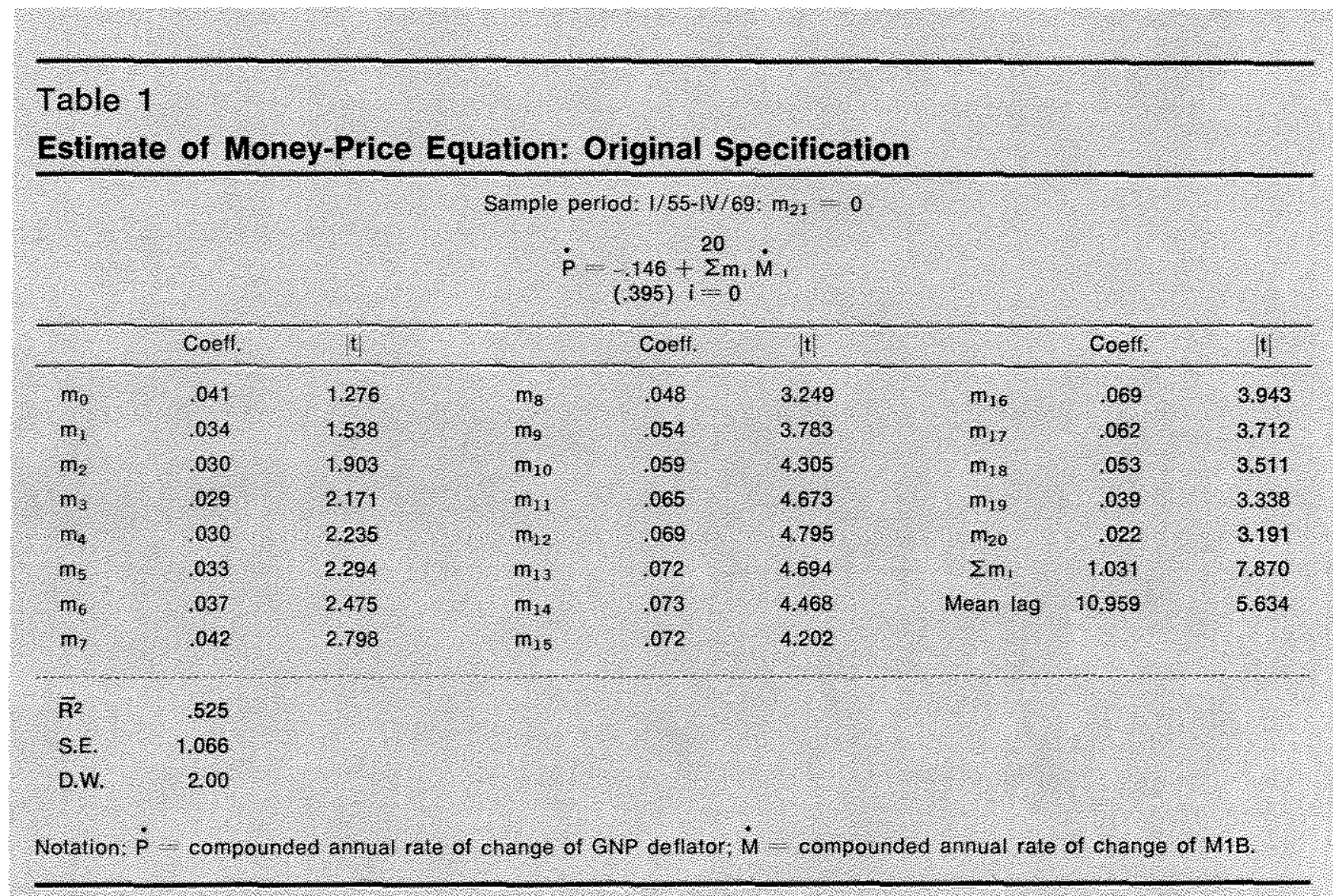

To examine the nature of the money-price lag in light of the experience of the 1970s, it is necessary to consider other factors that influenced the price level during this period. From August 1971 to April 1974, a govermment program of wage and price controls disrupted the money-price level link. In addition, in late 1973 and early 1974, substantial increases in energy prices occurred. At various times during the $1970 \mathrm{~s}$, agricultural conditions also appeared to affect movements in the price level or, more properly, in the indexes that are used to measure changes in aggregate prices.

Because of these factors, the basic price equation in this article has been respecified to include prices of food and energy relative to overall prices and dummy variables to capture nonmonetary effects of wage and price controls. Table 2 summarizes the results for the 1970.79 period (center columns) and, for comparison purposes, also summarizes the results of this same specification for the $1955-69$ period (lefthand column). As implied in Kamosky's specification, food and energy prices did not play a statistically significant role in explaining inflation during the 195569 period. $^{5}$

The results for $1970-79$ indicate a number of changes relative to those for 1955 69. The price control dummy is significant with a negative sign, and the post-control dummy has the expected (positive) sign but is not significant. The sum effect of energy prices, as measured by the producer price of fuels and related products and power, is positive and significant. The food price variable has the expected sign and is just short of being significant. More importantly, however, the pattern of coefficients on money is substantially different from that estimated for 1955 69. No coefficients are significant after the eighth lag, and the mean lag is 5.05 quarters. The sum of the coefficients, although close to one in value, is not significantly different from zero.

These results suggest that the 20 -quarter lag stmcture is no longer appropriate for data from the 1970s.

"Throughout this article, "statistical significance" refers to a two-tailed test conducted at the 5 percent level. For large samples, the critical " $\mathrm{t}$ " is tw.96. 


\section{Table 2}

\section{Estimates of Money-Price Equation: Moditied Specificalion}

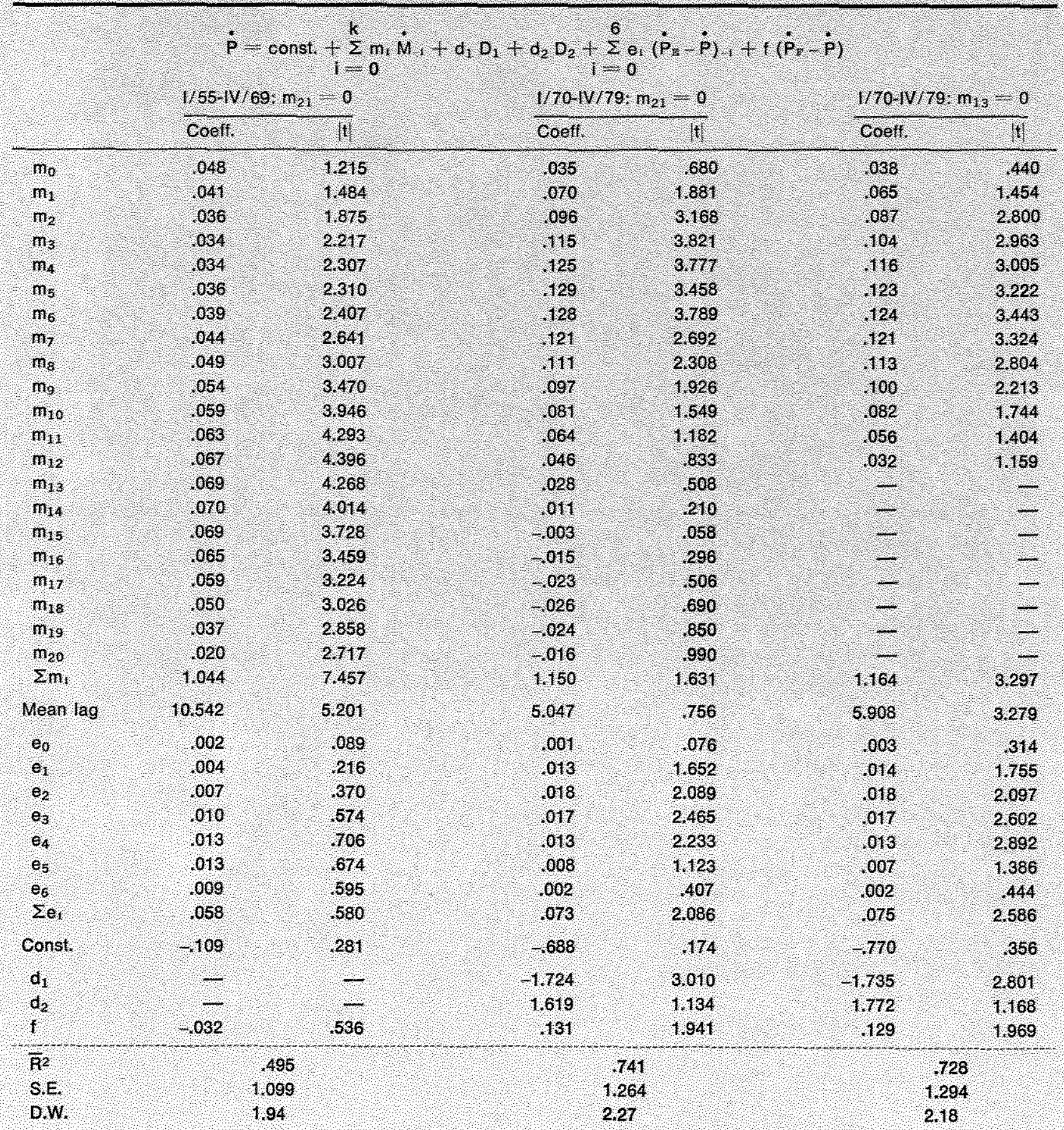

Notation: $\dot{P}=$ compounded annual rate of change of GNP deflator, $\dot{M}=$ compounded annual rate of change of $M 1 B$;

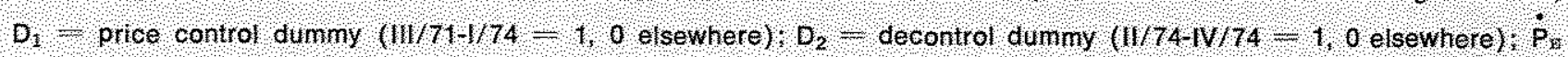
- compounded annual rate of change of producer price index of fuels and relaled products and power, and $\dot{P}_{\text {. }}$ compounded annual rate of change of lood detlator. 


\section{Chart 1 \\ Cumulative Effect on Rate of Price Increase of a Permanent Increase in the Rate of Growth of Money Percent of Total Eflect}

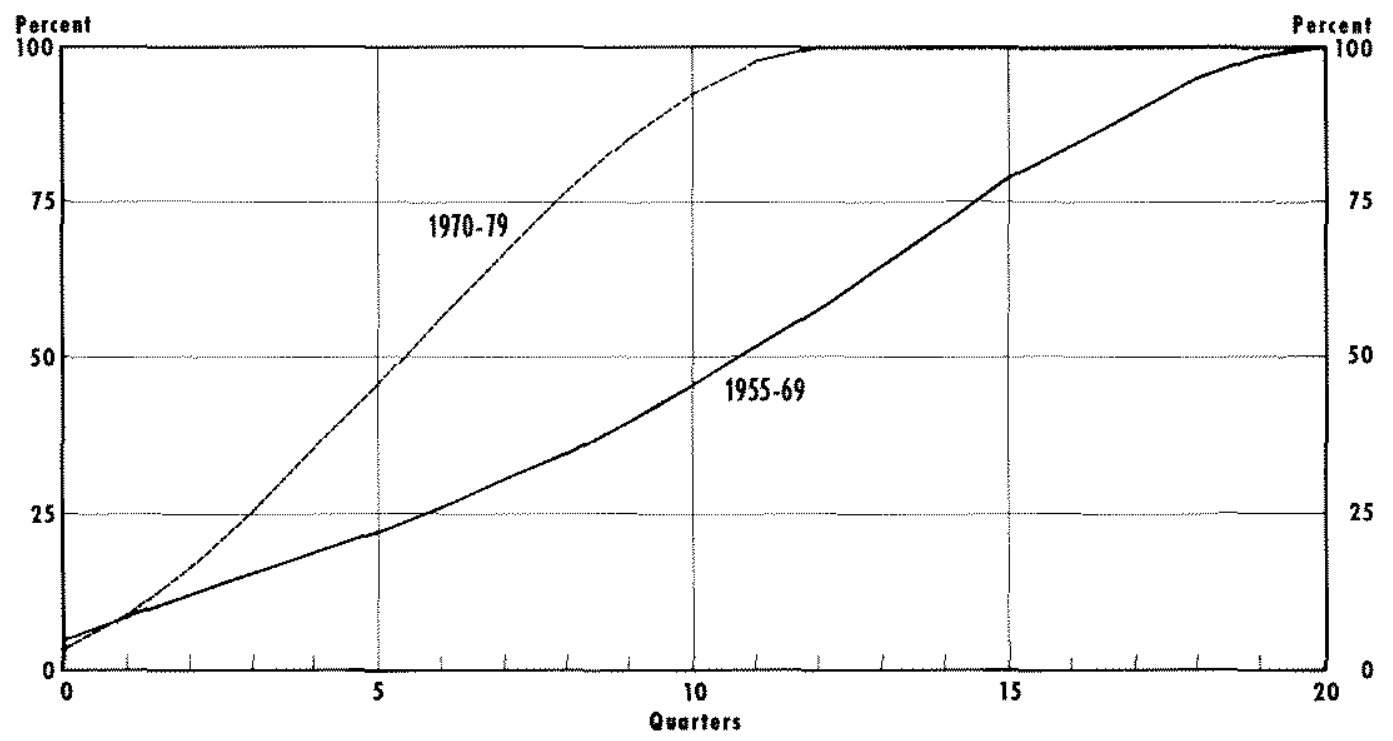

The results of shortening the lag structure to 12 quarters (with the thirteenth constrained to equal zero) are shown in the right-hand columns of table 2 . With this specification, the effect of money on prices equals slightly more than one after 12 quarters. The mean lag for the specification is 5.91 quarters, which is significantly different from the 10.54-quarter mean lag obtained for the 1955-69 period.

Chart 1 portrays the results from the left- and right-hand columns of table 2 and indicates that prices apparently responded more rapidly to changes in money during the 1970 s than previously. Why did this happen and what does it imply in terms of formulating a policy to combat inflation?

\section{Theoretical Rationale for Lags}

Questions about the lag between prices and money can be analyzed within the framework of information and search theory. ${ }^{6}$ To facilitate an understanding of lags and of the reasons they change, this article develops a theory of lag determination. ${ }^{7}$

6ost of the literature on information and search theory is in the context of labor markets. For a survey, see Steven A. Lippman and John J. MeCall, "The Economics of Job Search: A Survey," Economic Inquiry (June and September 1976 ) pp. $155-89,347-68$. For a tiscussion of the moneyprice lag within the context of rational expectations, see Bennett T. McCallum, "Price Level Adjustments and the Rational Expectations Approach to Macroeconomic Stabiliza-
Consider a typical firm that is a price-setter in an economic environment in which information regarding equilibrium prices and quantities is costly to obtain on both sides of the market. ${ }^{8}$ Firms do not possess full information about the prices or the quality of their competitors' products. Similarly, customers do not possess full information about the prices that all sellers are charging. Firms must determine whether a change in demand for their products is caused by a switch in consumer preferences or by a general shift in aggregate demand. Moreover, they have to decide whether such a shift is permanent or temporary.

For purposes of illustration, assume that the typical firm obtains information about the demand for its product by observing its sales at the current "posted" price. Given the fact that the firm possesses accumulated information on quantities sold at a given price and assuming that the firm knows its own cost structure, it will eventually learn which price is optimal for its operations.

tion Policy," Journal of Money, Credit and Banking (November 1978), pp. 418-36.

'Although the economics of information and search is not necessarily a theory of lag determination, this is a common. implication of the analysis, as it is usually applied.

${ }^{8}$ The classic article which develops this point is Kenneth J. Arrow, "Toward a Theory of Price Adjustment," in Moses Abramovitz, ed. The Allocation of Economic Resources (Stanford: Stanford University Press, 1959), pp. 41-51. 


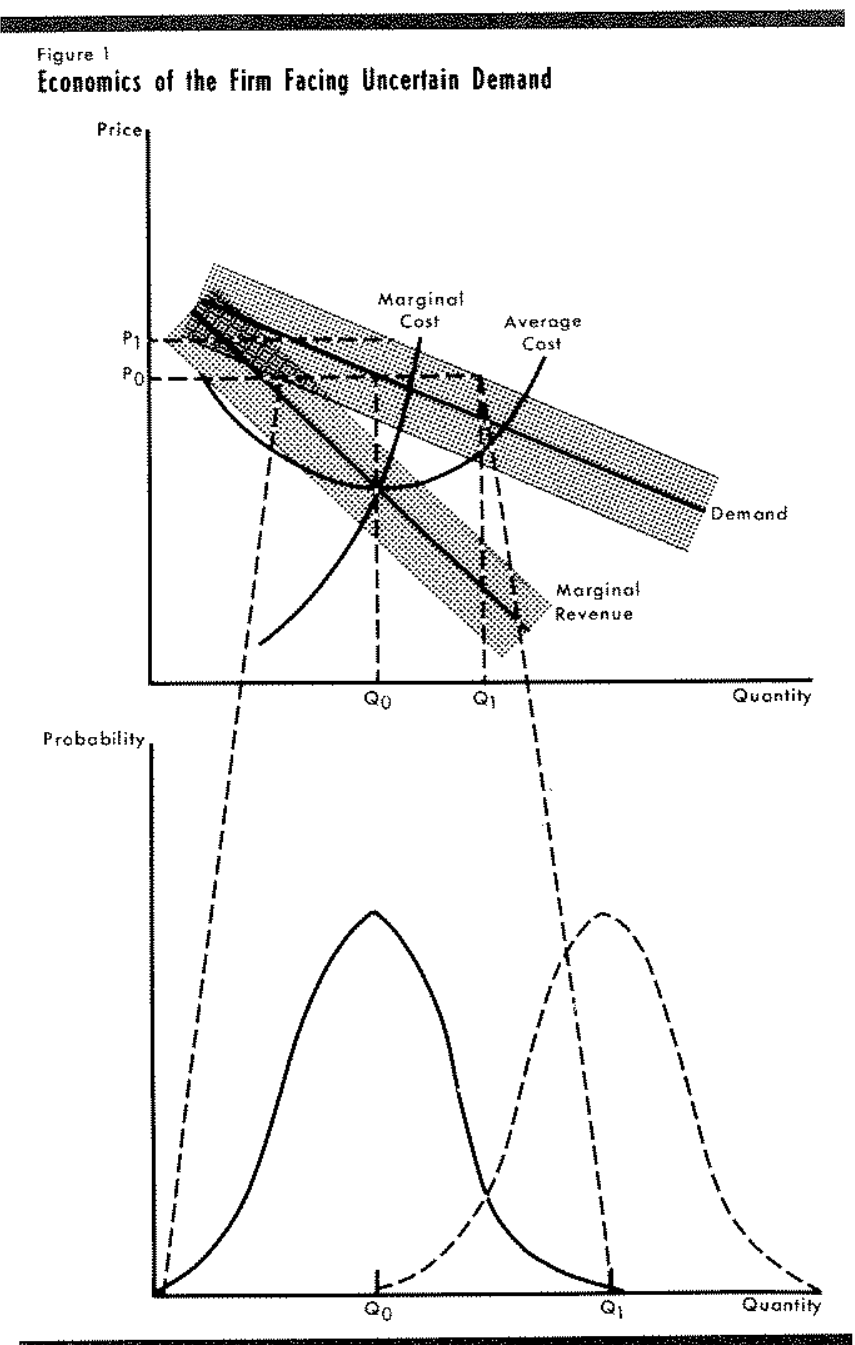

Figure I summarizes the situation for a typical firm. If costs and demand are known perfectly, $P_{0}$ and $\mathrm{Q}_{0}$ represent the profit-maximizing price and quantity. More realistically, perhaps, the demand curve can be viewed as the average rate of sales for given prices based on experience, with some "normally expected" variation around this average. For the sake of exposition, this demand curve is shown in the top half of figure $I$ as a band rather than a line, with the additional assumption being made that quantity sold at a particular price is distributed normally about the mean. The bottom half of figure 1 summarizes the nature of this demand curve in terms of a probability distribution. The solid line in the bottom half of figure 1 is a subjectively determined distribution that is based on sales experience, as well as other informational factors, when the price of the product is equal to $P_{0}$.

Each additional observation of quantity sold at $P_{0}$ will affect the firm's assessment of the nature of the distribution it faces. Suppose that, in a particular pe- riod, the firm realizes sales of $Q_{1}$ at price $P_{0}$; will it change its price? If demand shifts so that $Q_{1}$ is the mean of the new distribution, the profit-maximizing price would be $P_{1}$ (and the distribution as drawn with respect to $P_{ \pm}$will be slightly to the right of $\left.Q_{0}\right) .^{9}$ However, the firm will not change its price to $P_{1}$ unless its subjective assessment of the distribution has shifted accordingly; that is, the firm will change its price to $P_{1}$ only if the solid line shifts to coincide with the $Q_{1}$ distribution (drawn with respect to $P_{0}$ ).

In the absence of other information, it is reasonable to assume that the firm's subjective distribution will shift only slightly with a single observation, depending on past experience. Continued sales around $Q_{1}$ for a number of periods, however, would eventually shift the subjective distribution so that it would be centered over $Q_{1}$. Furthermore, the speed with which the firm will move to $P_{1}$ depends on the nature of the distribution around $Q_{1}$. If sales are distributed narrowly around $Q_{1}$, the firm will have greater confidence in the new distribution than if sales are distributed broadly. Over an extended period of time, the magnitude of price response will be the same but the speed of response will vary.

Even with a new subjective distribution, the firm will not immediately change its price. The fact that the process of adjusting price is costly will influence the firm's decision to change price. Changing price tags, making up new price lists, notifying salesmen, and/or reprogramming computers all involve costs. In addition, because firms do not know precisely what their competitors will do, a premature decision to increase price could result in a loss of customers. There is also a possible loss of customer goodwill if a firm changes price frequently, thereby shifting additional search costs to consumers. The change in sales must be both sufficiently large and perceived as relatively permanent before the firm will adjust its price.

\section{The Money-Price Lag in an Aggregate Context}

In a growing economy, firms will experience increasing sales over time and/or the number of firms will change. However, expansion of quantities sold need not imply rising prices. Prices will rise only if aggregate demand is shifting outward more rapidly

Note that nominal resource costs are assumed to be unchanged. In a general inflation, resource costs will also rise. The focus here is on the firm's response to a shift in aggregate demand. Recognition of such a shift before resource costs increase represents exploitable profit opportunities for the firm. 
than aggregate supply (which can be interpreted as a "suitable" aggregation of individual firms" marginal cost curves). If the position of the demand curve is dominated by movements in the stock of money, firms' assessments of demand will depend on their expectations of monetary growth. ${ }^{10}$

This reinterpretation of the money-price lag in an aggregate context can be illustrated in terms of figure 1. Qo represents an average level of sales for a given planning period and is associated with a given rate of monetary growth. The price will equal $\mathrm{P}_{0}$ if this expected monetary growth is realized. ${ }^{\text {i }}$ However, if the rate of monetary growth is higher than expected, sales averaging $Q_{1}$ (at price $P_{0}$ ) could be consistently realized. Firms will have to determine whether this change in monetary growth is permanent or temporary. Ultimately, firms must decide whether a price change is necessary. As explained earlier, a change in monetary growth will not necessarily lead to an immediate pricing response by firms. Profit-maximizing considerations will still determine whether the decision to change price should be made immediately or postponed until further information is obtained.

Reinterpretation of the analysis demonstrates how additional information influences the pricing process. Firms derive information about the state of demand by observing their sales. In an aggregate context, however, some connection between monetary growth and firms' sales will also apply. For example, if firms have observed a close relation between sales and monetary growth, their subjective distributions might shift significantly in anticipation of a change in monetary growth. In other words, firms' prices might be changed in anticipation of an increase in sales. ${ }^{12} \mathrm{In}^{-}$ formation about changes in monetary growth will reduce the lagged impact of money on prices. The whole process of determining price changes involves both sides of the market. If firms' customers have similar perceptions about monetary growth, they will expect prices to change, and firms" loss of customer goodwill, as a result of changing prices sooner, will be reduced.

10 See Leonall C. Axdersen and Jerry L. Joudan" "Monetary and Fiscal Actions: A Test of Their Relative Importance in Economic Stabilization," this Review (November 1968), pp. $11-24$.

11Different rates of expected monetary growth will, of course, imply different $\mathcal{F}_{0} \mathrm{~s}$, but costs will also be different so that $Q_{0}$ need not differ. The emphasis here, however, is on the decision to change price.

1'See Charles Pigot", "Expectations, Money, and the Forecasting of Inflation," Federal Reserve Bank of San Francisco Economic Review (Spring 1980), pp. 30 49.

\section{A Suggested Explanation of the Statistical Results}

The analysis suggests that when sales deviate from expected levels, price changes will eventually result. The length of the time interval between sales deviations and price changes will depend on the firm's perception that demand has shifted. This perception is conditioned by (1) the past history of inflation and monetary growth and (2) the distribution of recently observed deviations.

First, as shown by the results summarized in table 2, firms and their customers have developed a greater sensitivity to inflation and monetary growth during the 1970s. During the 1955-69 period, the response of prices to money was quite slow because the early part of the period was dominated by relatively slow inflation. As a result, during the latter part of the period, there was a tendency to consider higher rates of inflation and monetary growth as temporary. ${ }^{13}$ During the 1970 s, however, economic units began placing more emphasis on recent experience when forming their expectations; they leamed from their past errors.

Second, during the 1970 s, the nature of the distribution of deviations of money growth from what was expected (and, consequently, deviations of sales from what was expected) appears to have changed considerably. Some summary statistics are presented in table 3. Quarter"womquarter rates of change are examined for 20- and 12-quarter periods during the full 1955-79 period. These measures are examined to determine if the pattern of monetary growth has changed from the pattern observed for 1955-69.

The summary statistics that appear at the bottom of table 3 indicate that the results are mixed. The mean standard deviation, for example, changed little between the 1955-69 and the 1970-79 periods. However, the standard deviation of the means dropped sharply in the latter period, suggesting that the variation in monetary growth became more regular in the 1970s. This movement toward regularity suggests - although it does not necessarily imply - greater predictability. Nonetheless, tentative evidence appears to support the notion that monetary growth became more predictable in the 1970 s. $^{14}$

13This has been labeled the "return-to-normality" hypothesis. For discussion and statistical results, see David H. Resler,

"The Formation of Inflation Expectations" "this Review (April 1980), pp. 2-12.

14 The pattern of monetary growth would have to be examined more thoroughly, and probably in conjunction with a formal 


\section{Table 3}

\section{Summary of Monetary Growth. 1955-1979}

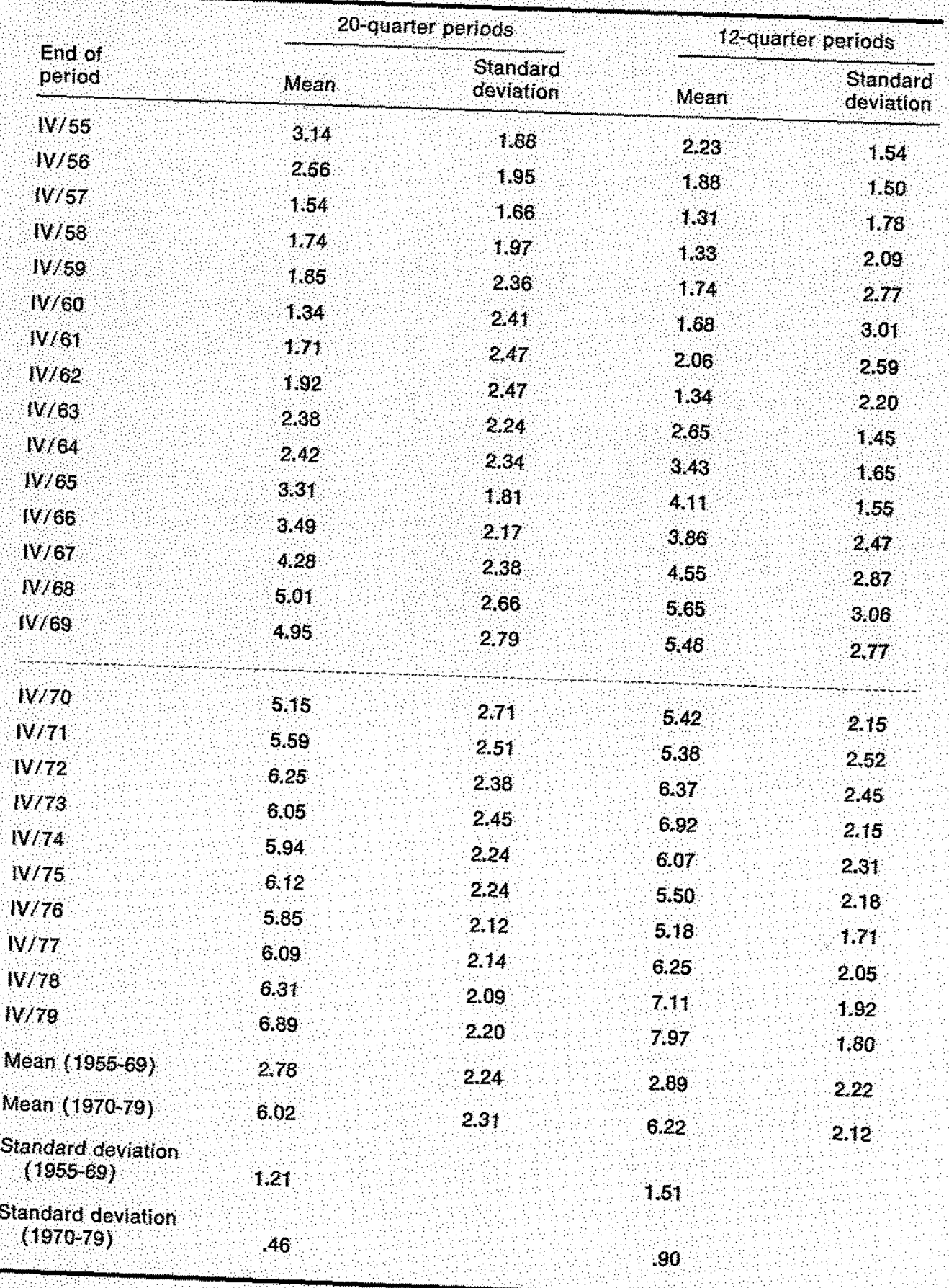

prediction model, before more defiritive conclusions could be developed. Expeotations formation is a complex proces fancy this process is probably still in fancy. More refined explanations of the shorfening of the lag
"Uwait further research. See, however, Robert J. Barro, United States Money, Output, and the Price Level in the United States," Journal of Political Economy (August 1978),
pp. 549-80. 


\section{Implications of the Analysis}

The lag in the effect of money on prices appears to have shortened during the $1970 \mathrm{~s}$, but the reasons for this contraction are unclear. One interpretation is that recent experience now receives more weight in the formation of expectations. Such a situation. would be beneficial for the policymaker, because it indicates that there is less inertia to be overcome in designing a policy to reduce inflation. On the other hand, a policy of short-run economic stimulus can give rise to a burst of inflation expectations, with little realized positive effect on output.

A second interpretation of the shortened lag be- tween money and prices is that it occurred because of the pattern of monetary growth. Although conclusions about the nature of the distribution of realized monetary growth are not definite, this interpretation implies that a steady reduction in monetary growth will result in less output loss than an erratic reduction. If both expected and actual monetary growth can be reduced simultaneously, the effect on output need not be severe or prolonged. ${ }^{15}$

15Past relationships based on an environment of uncertainty and continuing deviation of expected and realized monetary growth are misleading in assessing the costs of reducing intlation. See Laurence $H$. Meyer and Robert $H$. Pasche, "Or the Costs and Benefits of Anti-Inflation Policies," this Review (February 1980), pp. 3-14.

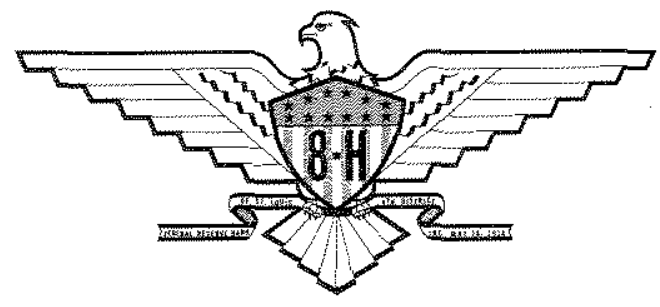

